\title{
A história da América Latina na Revista Desarrollo Económico dos anos sessenta do século passado
}

\author{
Heloisa Jochims Reichel* \\ Ana Paula da Silva Broniczack ${ }^{* *}$ \\ Débora Ehlert ${ }^{* * *}$
}

\begin{abstract}
Resumo:
O artigo analisa a historiografia sobre a América Latina, publicada no periódico argentino Desarrollo Económico - Revista de Ciencias Sociales, durante os anos sessenta do século passado, relacionando-a com a conjuntura política e o pensamento desenvolvimentista do período. Identifica os temas predominantes nos artigos publicados sobre a história latino-americana, destacando a questão da propriedade da terra, a influência da Revista Annales, o predomínio da história econômica e social e das novas metodologias de investigação utilizadas pelos historiadores. Na conclusão, ressalta a perspectiva do latino-americanismo, presente na maioria dos artigos historiográficos publicados na Revista, bem como para o fato de muitos deles estarem já vinculados às tendências atuais da historiografia Argentina e latino-americana.
\end{abstract}

Palavras-chave: Intelectuais, Revista Desarrollo Económico, anos sessenta, história da América Latina, história agrária, Revista Annales

Na América Latina, nos anos que antecederam a Revolução Cubana, ocorreu um certo equilíbrio entre a livre manifestação e a organização das forças políticas pró-EUA e as que se mostravam resistentes aos norte-americanos e, em alguns casos, até simpáticas ao modelo socialista. O período se caracterizou, igualmente, pela forte pressão exercida pelos EUA para que os países latino-americanos se alinhassem ao bloco capitalista de forma unívoca e coesa. Uma só voz para toda a América. A União Soviética, por sua vez, tentava marcar presença patrocinando organismos e sindicatos que propagavam e defendiam o comunismo ou auxiliando diretamente os governos que rompiam com os Estados Unidos, como aconteceu com o de Cuba após a revolução. Do ponto de vista econômico, a prosperidade e a estabilidade dos países ricos colocavam, na pauta de discussões de políticos e de intelectuais latino-americanos, os problemas dos países mais atrasados e a necessidade de criar políticas de ação que revertessem essa situação.

HISTÓRIA, SÃO PAULO, v. 25, n. 1, p. 203-225, 2006 
No início dos anos sessenta, já com a Revolução Cubana em desenvolvimento e a Aliança para o Progresso organizada, o bipolarismo ideológico que caracterizou a Guerra Fria ganhou força em toda América Latina. Num espaço em que se faziam sentir, ao mesmo tempo, as estratégias de domínio econômico e ideológico dos EUA e as tentativas de maior penetração do comunismo, a sociedade latino-americana, especialmente a sua intelectualidade, vivenciou uma etapa crítica do desenvolvimento da autoconsciência latino-americana. Nesse momento, a dimensão América Latina se sobressaiu mais uma vez, realizando-se todo um esforço de interpretação sobre sua realidade atual e passada. Tinha-se a convicção de que sua tormentosa história havia entrado numa etapa decisiva e resolutiva. Isso acabou por dar uma eficácia nova a motivos nada novos na consciência latino-americana, como o que postula uma unidade de origem e destino para a região, contribuindo, por outra parte, para que se conhecessem melhor as peculiaridades sobre alguns temas ligados a sua história.

Nos anos sessenta, os intelectuais, aproveitando o reconhecimento social de que gozavam tanto para atuar como consciência da sociedade quanto para propor as transformações que achavam necessárias, atuavam engajados na vida política e social do continente. ${ }^{1}$ Dois fatores contribuíram para isso: a influência que a concepção de intelectual formulada por Antonio Gramsci exercia entre grande parte da intelectualidade ${ }^{2}$ e o status de saber privilegiado que era conferido, pela sociedade, às ciências sociais, principalmente à sociologia. ${ }^{3}$ Conjugados, eles propiciaram a legitimidade e o privilégio com que o setor participou no debate sobre a realidade latino-americana, ou de alguns de seus países, colocando-os a serviço das causas que defendiam.

Pródiga foi, assim, a produção intelectual da época e muitas foram as tendências teóricas e ideológicas seguidas. Afinal, vivíamos anos intensos da Guerra Fria. Neste contexto, várias disciplinas passaram a desenvolver estudos sobre a realidade, buscando o conhecimento da sua totalidade através da análise das grandes estruturas. A economia, que reinara nos anos cinqüenta, agora dividia espaço com outras áreas como a antropologia, a sociologia, a ciência política, a história ou a geografia. A produção historiográfica, especialmente, foi significativa. Tanto historiadores quanto cientistas sociais e economistas se preocuparam em analisar o processo histórico latino-americano com o objetivo de avaliar as condições para a mudança pretendida

A metodologia utilizada para a análise da produção historiográfica que visamos realizar consistiu na seleção e análise de artigos publicados em periódicos. Em parte, ela 
foi condicionada pela abundância e pela diversidade da produção intelectual da época, bem como pela impossibilidade de reunir, na íntegra, a produção individual dos autores que para ela contribuíram. Porém, é importante afirmar sua validade e pertinência para com nossos objetivos. Sirinelli (in Rémond, 1996, pp. 248-249) já destacou que as revistas se apresentam como meio importante para alcançar um conhecimento mais bem organizado acerca da produção intelectual, tendo em vista que, através da seleção feita pelos conselhos editoriais, dos laços de amizade e de confiança que se estabelecem entre autores e leitores, ou até mesmo pelo repúdio que despertam, elas vão formando "redes", através das quais é possível identificar a estrutura do campo intelectual.

Partindo desse entendimento, focalizamos, neste artigo, a Revista Desarrollo Económico - Revista de Ciencias Sociales - (D.E.) e mais especificamente a historiografia que ali foi publicada, de abril de 1961 a abril de 1971. Esse período corresponde à primeira década de existência do periódico e, também, por seguir-se à Revolução Cubana, a um momento de grande radicalização das posições políticas e ideológicas na América Latina. Nosso objetivo é desvendar a "rede" de intelectuais que ela congregou, quais as idéias centrais, as propostas e as tendências teóricometodológicas que ela divulgou no que diz respeito à história da América Latina. Para tal, formulamos algumas questões como: Por que a história se faz presente numa revista de orientação fundamentalmente econômica? Como interpretou a história da América Latina? Com que finalidade a analisou?

A Revista Desarrollo Económico possui um crédito que a destaca entre muitos outros periódicos latino-americanos e especialmente argentinos. Vem sendo publicada semestralmente de forma ininterrupta desde seu lançamento, em $1961^{4}$, até os dias de hoje, tendo resistido a inúmeras conjunturas políticas e econômicas adversas. ${ }^{5} \mathrm{~A}$ instituição responsável por sua edição é o Instituto de Desarrollo Económico y Social (I.D.E.S.), associação civil sem fins lucrativos, de índole acadêmica, dedicada ao estudo de temas econômicos, políticos e culturais. ${ }^{6}$

O I.D.E.S. foi fundado em 1960, por um grupo de cientistas sociais que buscava estimular e promover o trabalho interdisciplinar no meio acadêmico. Um ano após, ao assumir a responsabilidade pela edição da Revista, introduziu-lhe a mesma marca e tornou-a o seu meio de comunicação com a sociedade. ${ }^{7}$ No editorial do volume em que foram comemorados os vinte e cinco anos da Revista, o Comitê Editorial assim se manifestou: 
El IDES y nuestra revista nacieron, hace veinticinco años, de una conjunción de esfuerzos de científicos sociales. El aporte inicial provido esencialmente de tres grupos: por un lado, un conjunto de economista que acompañaron la gestión de Aldo Ferrer como ministro de Economía de la provincia de Buenos Aires, entre los que estaba Norberto González, primer presidente del IDES; por otro, historiadores, sociólogos y politólogos nucleados en torno del Instituto de Sociología de la Universidad de Buenos Aires; y, por último, por investigadores del Instituto Di Tella - por entonces la única institución privada importante de investigación en ciencias sociales en el país. ${ }^{8}$

Essas palavras indicam que, no periódico, apesar de predominarem as análises de ordem econômica e social, inerentes à orientação do seu vínculo institucional, havia o interesse em realizar um trabalho conjunto com as diversas disciplinas sociais, inclusive com a história. Essa tendência, que para os dias de hoje é recorrente, aparecia como bastante inovadora nos anos sessenta.

Em sintonia com o clima de otimismo e esperança existente entre os intelectuais da época em que foi criada e seguindo os propósitos de debate acadêmico e de intervenção cultural, a D. E. buscou colocar, no centro da reflexão, a problemática do desenvolvimento e da modernização. Além do viés econômico e da valorização das Ciências Sociais ${ }^{9}$, características apontadas em seu nome, uma forte influência do pensamento cepalino foi exercida sobre os fundadores e responsáveis pela primeira década de edição, como também sobre toda a rede de intelectuais que com ela contribuíram. Sobre isso, os editores referiram no balanço dos vinte e cinco anos:

El contexto en que se desenvolvieron las actividades en los primeros años ejerció una influencia positiva. Recordemos: en el plano latinoamericano era una época de intensa y, en muchas áreas, pionera actividad de la CEPAL de Raúl Prebisch; y en el plano local se vivian momentos que ahora podemos juzgar como excepcionales en la Universidad Nacional de Buenos Aires, bastando mencionar el desarrollo de áreas como sociología, historia social y economía (en procesos a cuyo frente estaban Gino Germani, José Luis Romero y Julio H. G. Olivera, respectivamente). ${ }^{10}$

Instalada no ano de 1948 em Santiago do Chile, como escritório regional da ONU, a Comissão Económica para a América Latina (Cepal) foi constituída por intelectuais latino-americanos que definiram a América Latina e seu desenvolvimento como objeto primordial de sua reflexão. Com a autoridade de um organismo internacionalmente reconhecido, a Cepal, em seus primeiros anos, produziu um pensamento autóctone latino-americano que se concentrou em criticar a orientação 
liberal vinda das nações desenvolvidas e defender a necessidade de reformas estruturais na economia e na sociedade dos países periféricos. De acordo com sua posição estruturalista, contrária ao monetarismo dos países centrais do capitalismo, ela defendeu o fim da divisão internacional do trabalho que separava países industrializados - centro - de países não industrializados - periferia. A seu ver, o crescimento econômico, iniciado por volta de 1880 e orientado para as exportações de bens primários, era a causa do posterior estancamento e atraso da região.

Os países da América Latina deveriam implementar, com a forte coordenação e planejamento do Estado, a industrialização substitutiva de importações, única alternativa ao desenvolvimento da região. Para tal, era necessário estimular a relação da agricultura com a indústria, fazendo que esta absorvesse a mão-de-obra excedente do mundo rural, visse aumentadas as capacidades de consumo do mercado interno e, por extensão, de acumulação de capital. Essas condições seriam alcançadas através das reformas na estrutura produtiva, principalmente das que atuariam no combate à concentração da renda e da propriedade. ${ }^{11}$

Raul Prébisch, economista argentino que presidiu o organismo por mais de uma década, exerceu forte influência sobre seus pares e conterrâneos, principalmente através da obra fundante do pensamento cepalino, El desarrollo económio de América Latina y algunos de sus principais problemas, publicada em 1949. Ao defender a industrialização baseada na substituição de importações e não na produção industrial voltada ao mercado internacional, mais competitivo, a Cepal estimulou, assim, naqueles anos, o debate em torno das reformas estruturais que aumentassem o nível de renda interna nos países e que criassem mercado para os produtos da indústria nacional que substituía importações.

A história e a historiografia do período - Nesse contexto cultural e ideológico, a história foi considerada uma das disciplinas que melhor contribuição podia fornecer ao debate acadêmico e à atuação do Estado $^{12}$. Começou a se fazer presente, entre os intelectuais latino-americanos, a preocupação de analisar o passado a partir da história econômica e social. Nesse sentido, viram-se estimulados, também, pelo destaque que esse campo historiográfico ganhara na Europa e nos Estados Unidos desde o fim da segunda guerra mundial ${ }^{13}$.

A história econômico-social aparecia renovada pelos estudos sobre as elites, focalizadas como agentes centrais da configuração da sociedade moderna latinoamericana e pelas investigações das séries econômicas. Como disse Sarlo (2001, p. 89): 
Una historia económica sensibilizada por lo político y lo institucional, una historia política tradicional, abierta a temas sociológicos, ésas serían las líneas principales de los nuevos estudios históricos que, como sucedió en la escuela francesa de lês Annales, dialogan intensamente con las ciencias sociales.

Os anos que focalizamos em nossa análise correspondem a um período de inquietação mundial no que diz respeito ao que devesse ser a história e, por conseguinte, a construção do conhecimento histórico. O novo momento historiográfico foi marcado, na Argentina, pela publicação de duas obras que reuniram uma nova geração de intelectuais composta por historiadores e cientistas sociais que dariam espaço à renovação da historiografia nacional. Em 1965, Torcuato Di Tella, Gino Germani e Jorge Graciarena editaram um livro, pela Eudeba ${ }^{14}$, com o título Argentina, sociedad de masas. Além dos editores, colaborou, no volume, o historiador Túlio Halperin Donghi. ${ }^{15}$ Em 1969, a união deste com o sociólogo Torcuato Di Tella resultou na publicação da obra Los fragmentos del poder, emblemática não apenas para demonstrar a relação entre as ciências sociais e a história, mas, também, para mostrar o estado em que se encontrava o conhecimento histórico. ${ }^{16}$

O diálogo com a política também foi intenso, devido à conturbada conjuntura política vivida pelo país nos inícios dos anos sessenta. Na Argentina, a construção do conhecimento histórico sempre sofrera a influência do processo político nacional. A história política atuou como uma variável importante, senão definidora, porque o país não possuía uma tradição historiográfica baseada numa sucessão de escolas que se distinguissem por apresentar um viés teórico-metodológico independente das influências estrangeiras. As mudanças ou interrupções que haviam marcado o processo historiográfico até então mais se deviam a motivos políticos do que ao esgotamento dos paradigmas, dos objetos ou dos temas estudados.

Sob essa perspectiva, a historiografia, até aquele momento, fora fortemente influenciada pela dupla pretensão de, por uma parte, compreender a antinomia barbárie e civilização e, por outra, dar conta do problema da invenção da nação. Tendo se iniciado quando da implantação do sistema federal de governo, sob a liderança de setores da elite dominante que professavam o liberalismo e o progressismo, ela sofreu a influência do positivismo principalmente e se apresentou sob duas vertentes, acadêmica ou tradicional e revisionista. 
A Revista D. E. surgiu num período de "pandemônio ideológico"17, que gerava uma grande instabilidade política. Perón havia sido deposto pela chamada revolução libertadora em 1955, mas o país percebia que o peronismo continuava vivo como força política. A coalizão de forças que derrubara o presidente e que buscava restituir, à grande burguesia, o pleno controle da vida nacional, sofreu fraturas internas após a vitória e não conseguiu resistir à pressão das massas, nem destruir o movimento operário organizado e as alternativas de esquerda. O general Pedro Aramburu, que governara ditatorialmente desde 55 , foi obrigado a convocar eleição presidencial, da qual saiu eleito Arturo Frondizi.

Frondizi realizou um governo que pactuou com Perón desde o exílio, com o objetivo de possibilitar o retorno do peronismo à cena política. Por outro lado, deu continuidade à política econômica do governo anterior e à posição das forças armadas como definidoras da linha político-ideológica do governo. Essa contradição foi responsável pela sua deposição em 1962, sendo seu governo concluído pelo Presidente do Senado, Jose Maria Guido, que governou sob a tutela das forças armadas, sem Congresso e sem liberdade política. O governo do presidente Guido se desenrolou em condições de instabilidade permanente. À crise econômica e política, seguiu-se uma fratura no interior das forças armadas, que possibilitou a realização de novas eleições presidenciais em 1964. Eleito Arturo Illia, esse não chegou a governar mais do que dois anos. Foi deposto por uma facção militar que, através de uma junta de comandantes, elegeu o general Juan Carlos Ongania como presidente da República. Este, inspirado no que ocorria no Brasil, colocou em prática uma política militarista desenvolvimentista. $\mathrm{O}$ governo de Onganía procurou eliminar tudo que fosse comoção, enfrentamento, debate, assim como as pressões e demandas dos grupos majoritários que se expressavam através de organizações e mobilizações autônomas. Negou o pluralismo político e pretendeu extirpar a instância política como ordem institucional legítima, substituindo-a pelo estado autoritário técnico-burocrático.

Em julho de 1966, adotou a medida que mais convulsionou a vida acadêmica e intelectual na Argentina. Interveio nas universidades públicas, impondo um regime de controle rígido associado a uma liberdade vigiada a estudantes e professores que, em muitas faculdades, se demitiram em grande número. Túlio Halperin Donghi, um deles, foi atuar em Berkeley, Estados Unidos.

Desde a queda de Perón, a universidade, que apoiara a revolução libertadora em 1955, se tornara reduto das diversas tendências políticas e ideológicas e evidência do 
caleidoscópio social que compunha a sociedade argentina. José Luis Romero, quando reitor da Universidade de Buenos Aires, em 1956, expressou o que se esperava da universidade naquele momento:

Todo retorno - sea a la Universidad de 1943, sea a la de 1930 o a la de 1923 - es inútil y absurdo, y a la larga el esfuerzo que hiciéramos para lograrlo resultaría estéril. Es necesario, pues, hacerse cargo de todo lo que en el país se ha transformado desde 1930 e tenerlo presente para que la Universidad no defraude sus necesidades y sus exigencias. Para un país que ha crecido, que ha modificado su estructura social, que ha removido ciertos valores tradicionales y que ha sufrido, no lo olvidemos, la extraña seducción del fascismo, es necesario hacer una Universidad profundamente renovada y socialmente eficaz. Si uno de sus objetivos fundamentales debe ser alcanzar el más alto nivel científico, otro no menos importante debe ser dotarla de la sensibilidad suficiente como para que sirva al desarrollo social del país formando minorías que no persigan privilegios y que estén animadas por la convicción de sus deberes frente a la sociedad. ${ }^{18}$

É compreensível, pois, que as medidas francamente repressivas, impostas pela intervenção de 1966, tenham produzido, poucos anos depois, uma gigantesca politização dos estudantes, a qual daria lugar à curta experiência da "universidade nacional e popular", ocorrida em 1973 durante o governo de Héctor Cámpora e pouco antes do retorno de Perón ao poder. ${ }^{19}$

De modo que, nos anos sessenta, culminando nos inícios dos setenta, a sociologia e a história se politizaram a limites altíssimos, influenciando a produção historiográfica. A D. E., entretanto, procurou atuar como receptora e divulgadora da importância que era dada ao conhecimento do passado e das tendências historiográficas que influenciavam os historiadores no momento, sem se deixar contaminar demais pela conturbada conjuntura política que o país atravessava. Isso se faz perceber através do perfil do intelectual que publicava na Revista. Nesse sentido, a característica básica que deveria apresentar o intelectual participante da rede que a Revista configurava era a de ser um acadêmico voltado à investigação documental, além de engajado no processo político. A partir dessa postura, que fazia parte da concepção de intelectual na época, os autores dos artigos deveriam realizar análises interpretativas e críticas da realidade, deixando para trás os ensaios de ordem cultural e filosófica. As contribuições à Revista deveriam estar baseadas em pesquisas científicas, realizadas a partir de rigor metodológico.

Os intelectuais do período, de maneira geral, eram divididos em grupos e denominados conservadores, reformistas e revolucionários. Estes, mais radicais e 
defensores da luta de classes como categoria fundamental para analisar a sociedade, consideravam-se os únicos intelectuais de esquerda. Os reformistas, entretanto, não entendiam assim, incluindo-se, também, no grupo de esquerda. Estes foram os que predominantemente publicaram na D.E. Tinham posições de crítica em relação à política nacional, procuravam transformar a realidade nacional, mas sem o radicalismo ideológico dos revolucionários.

Um dos autores de maior destaque na rede formada pelos intelectuais da D.E. foi Gino Germani. Seu primeiro livro, Estructura social de la Argentina, publicado em 1955, introduziu na Argentina o espírito da nova sociologia, entendida como disciplina empírico-analítica, de acordo com a escola norte-americana. Apesar de ter batalhado pelo que chamou de sociologia científica e ter influenciado a primeira geração de sociólogos e de historiadores que se formou após o peronismo, a partir de 1966, Germani assistiu seu prestígio declinar.

Nesse ano, quando ocorreu a intervenção militar na universidade, outra mudança começava a se fazer sentir no pensamento dos intelectuais. O giro político, mais do que intelectual, fez que a teoria da dependência, que proporcionava hipóteses mais de acordo $^{20}$ com o clima radical dos anos sessenta, começasse a predominar nas análises que buscavam explicar o trânsito entre as sociedades tradicionais e as modernas. O modelo de Germani passou a ser considerado reformista, progressista, preso aos acontecimentos e marcado pela idéia evolutiva que dissimulava a luta de classes.

A América Latina na D.E. - Em quase todos os volumes da Revista editados na década de sessenta, há artigos de conteúdo histórico, sendo vários de autoria de historiadores. A América Latina, sob o enfoque multidisciplinar, também foi objeto constante dos artigos publicados. Alguns foram exclusivamente dedicados à História da América Latina, como a edição especial, consubstanciada no volume 3, de abrilsetembro de 1963. Os editores responsáveis por ele, Roberto Cortes Condes e Ezequiel Gallo, autores de obras fundamentais sobre a modernização da Argentina, apontaram os transtornos ocasionados pelos processos de crescimento nos países da região como as razões que tornavam necessária a análise da formação histórica dos mesmos.

Três temas aparecem como norteadores das análises históricas sobre a América Latina que foram publicadas na D.E. durante os anos sessenta, todas elas sob forte influência do pensamento cepalino e da história econômico-social. São eles: a modernização da estrutura econômico-social ocorrida com a inserção da América Latina na divisão internacional do trabalho, o desenvolvimento industrial que se iniciou no 
mesmo período e a estrutura da propriedade da terra herdada dos períodos colonial e proto-independente.

A modernização da estrutura produtiva, realizada a partir da segunda metade do século XIX e primeiras décadas do século vinte, é vista como promotora de mudanças nas estruturas econômica e social, quando os interesses do capitalismo mundial, associados à estabilidade política alcançada pelos países da América Latina (bem entendido, apenas nos que a alcançaram), orientaram os investimentos públicos e privados para a modernização da economia exportadora e conseqüente inserção da região na divisão internacional, modelo que pautava a estrutura do mercado internacional e o desenvolvimento do capitalismo na época. Convém destacar, entretanto, que, para os cepalinos, a modernização da estrutura produtiva realizou-se, preservando elementos da estrutura colonial, como o latifúndio e a economia agroexportadora, considerados os principais responsáveis pelo atraso do desenvolvimento latino-americano.

Alguns estudiosos, que seguiam a teoria da modernização de Gino Germani, viram essa transformação de forma positiva. Para eles, a modernização da economia com vistas ao atendimento das demandas internacionais não repercutiu apenas na estrutura produtiva dos produtos agroexportadores. A divisão social do trabalho, melhorando o nível salarial e exigindo mão-de-obra mais qualificada, acabou por propiciar o crescimento do mercado interno e o desenvolvimento urbano, gêneses das condições que seriam responsáveis para dar início à produção industrial na América Latina.

Cepalinos e adeptos da teoria da modernização destacaram a temática da industrialização em seus artigos. Para os primeiros, principalmente, o foco primordial a ser considerado e analisado acerca do processo de industrialização deveria ser o surgimento da indústria nacional, voltada para o consumo interno e formada por capitais nacionais. O início desse processo, quando ainda o que ocorria era o desenvolvimento industrial e não o processo de industrialização propriamente dito ${ }^{21}$, foi tema de muitos dos artigos publicados na D. E.

A questão da concentração da terra também despertou o interesse dos articulistas da Revista. Considerando essa temática, os períodos colonial e proto-independente foram motivos de atenção por parte dos historiadores, pois eram vistos como sendo os momentos em que surgiram e/ou se consolidaram os latifúndios, um dos principais entraves ao desenvolvimento da América Latina ainda em meados do século $\mathrm{XX}^{22}$. Por 
seus reflexos não só na produção, mas também na sociedade, na política e na cultura dos países latino-americanos, a questão da propriedade da terra foi, assim, objeto de análise de muitos artigos publicados na D.E.

Tabela 1. Artigos sobre História da América Latina, publicados na Revista Desarrollo Económico entre os anos $\underline{1961 / 1971 .}$

\begin{tabular}{|c|c|c|}
\hline Título do artigo & Autor & Revista/ N. / Vol./ Ano \\
\hline $\begin{array}{l}\text { La estructuración económica en la } \\
\text { etapa formativa de la Argentina } \\
\text { moderna. }\end{array}$ & Sergio Bagú & D.E., n. 02, Vol. 01, jul./ set. 1961 \\
\hline $\begin{array}{l}\text { La generación del } 80 \text { y su projecto: } \\
\text { Antecedente y consecuencias. }\end{array}$ & $\begin{array}{l}\text { Oscar E. Cornblit, Ezequiel Gallo (h.) } \\
\text { y Alfredo A. O'Connell }\end{array}$ & D.E., n. 04, Vol. 01, ene./mar. 1962 \\
\hline El desarrollo agropecuario. & Horacio Gilberti & D.E., n. 01, Vol. 02, abr./jun. 1962. \\
\hline $\begin{array}{l}\text { La expansión Ganadera en la } \\
\text { Campaña de Buenos Aires. (1810- } \\
\text { 1852) }\end{array}$ & Túlio Halperin Donghi & D.E., n. 1-2, Vol. 03, abr./set. 1963. \\
\hline $\begin{array}{l}\text { La formación de los Partidos Políticos } \\
\text { Contemporáneos }\end{array}$ & Ezequiel Gallo/ Silvia Sigal & D.E., n. 1-2, Vol. 03, abr./set. 1963. \\
\hline $\begin{array}{l}\text { Problemas del Crecimiento industrial } \\
\text { de la Argentina. (1870-1914) }\end{array}$ & Roberto Cortes Conde & D.E., n. 1-2, Vol. 03, abr./set. 1963. \\
\hline $\begin{array}{l}\text { Una revolución agrícola en la } \\
\text { Argentina. }\end{array}$ & James R. Scobie & D.E., n. 1-2, Vol. 03, abr./set. 1963. \\
\hline $\begin{array}{l}\text { Hacia un "modelo intercontinental": } \\
\text { La expansión europea en ultramar } \\
\text { entre } 1500 \text { y } 1800 \text {. }\end{array}$ & F. Mauro & D.E., n. 1-2, Vol. 03, abr./set. 1963. \\
\hline $\begin{array}{l}\text { Movimiento de los precios } \mathrm{y} \\
\text { desarrollo económico: el caso de } \\
\text { Sudamérica en el siglo XVII. } \\
\end{array}$ & Rugiero Romano & D.E., n. 1-2, Vol. 03, abr./set. 1963. \\
\hline $\begin{array}{l}\text { La gran propiedad en México desde } \\
\text { siglo XVI hasta comienzos del siglo } \\
\text { XIX. }\end{array}$ & François Chevalier & D.E., n. 1-2, Vol. 03, abr./set. 1963. \\
\hline La mesa de tres patas & Claudio Veliz & D.E., n. 1-2, Vol. 03, abr./set. 1963. \\
\hline $\begin{array}{l}\text { El parlamento argentino en épocas de } \\
\text { cambio: } 1889,1916,1946 .\end{array}$ & Dario Cantón & D.E., n. 13, Vol. 04, abr./jun. 1964. \\
\hline $\begin{array}{l}\text { Antecedentes y perspectivas de la } \\
\text { Asociación Latinoamericana de Libre } \\
\text { Comercio }\end{array}$ & José María Dagnino Pastore & D.E., n. 14-15, Vol. 04, jul./dic. 1964 \\
\hline $\begin{array}{l}\text { Las consecuencias económicas y } \\
\text { sociales de las políticas económicas } \\
\text { ortodoxas aplicadas en la República } \\
\text { Argentina durante los años de } \\
\text { posguerra. }\end{array}$ & Eprime Eshag y Rosemary Thorp & D.E., n. 16 Vol. 04, ene./mar. 1965 \\
\hline $\begin{array}{l}\text { Populismo y reforma en América } \\
\text { Latina }\end{array}$ & Torcuato S. Di Tella & D.E., n. 16 Vol. 04, ene./mar. 1965 \\
\hline $\begin{array}{l}\text { Cambios históricos en la estructura de } \\
\text { la producción agropecuaria en la } \\
\begin{array}{l}\text { Argentina. Utilización de los } \\
\text { recursos. }\end{array}\end{array}$ & Roberto Cortés Conde & D.E., n. 20 Vol. 05, ene./mar. 1966 \\
\hline $\begin{array}{l}\text { Origen y evolución de la pequeña } \\
\text { propiedad campesina en La Pampa } \\
\text { seca argentina. (El caso de la } \\
\text { provincia de La Pampa) }\end{array}$ & Romain Gaignard & D.E., n. 21 Vol. 06, abr./jun. 1966 \\
\hline $\begin{array}{l}\text { Fragmentos de la carta de Jamaica del } \\
\text { general Simón Bolivar }\end{array}$ & & D.E., n. 22-23 Vol. 06, jul./dic. 1966 \\
\hline $\begin{array}{lcc}\text { Desarrollo } & \text { y } & \text { estancamiento en } \\
\text { América } & \text { Latina } & \text { (Enfoque }\end{array}$ & Celso Furtado & D.E., n. 22-23 Vol. 06, jul./dic. 1966 \\
\hline
\end{tabular}




\begin{tabular}{|c|c|c|}
\hline estructuralista) & & \\
\hline $\begin{array}{l}\text { Los Problemas Agrarios en la } \\
\text { América Latina de } \\
\text { Indígena. }\end{array}$ & François Chevalier & D.E, n. 22-23, Vol. 06, jul./dic. 1966. \\
\hline $\begin{array}{l}\text { Sociedades esclavistas en las } \\
\text { Américas. Un estudio comparativo. }\end{array}$ & Herbert S. Klein & $\begin{array}{l}\text { D.E., n. 22-23, Vol. 06, jul./dic. } \\
1966 .\end{array}$ \\
\hline $\begin{array}{l}\text { Los radicales argentinos y la defensa } \\
\text { de los intereses ganaderos, 1916-1930 }\end{array}$ & Peter Smith & D.E., n. 25 Vol. 07, abr./jun. 1967 \\
\hline $\begin{array}{l}\text { Algunos rasgos de la expansión } \\
\text { territorial en Argentina en la segunda } \\
\text { mitad del siglo XIX }\end{array}$ & Roberto Cortés Conde & D.E., n. 29 Vol.08, abr./jun. 1968 \\
\hline El laberinto bolivariano & Torcuato S. Di Tella & $\begin{array}{l}\text { D.E., n. 30-31, Vol. 08, jul./dic. } \\
1968 .\end{array}$ \\
\hline $\begin{array}{l}\text { El Congreso de Panamá: bolivarismo } \\
\text { y monroísmo. }\end{array}$ & Indalecio Liévano Aguirre & $\begin{array}{l}\text { D.E., n. 30-31, Vol. 08, jul./dic. } \\
\text { 1968. }\end{array}$ \\
\hline $\begin{array}{l}\text { Tierra y trabajo en Nueva Granada, } \\
1760-1845 \text {. }\end{array}$ & William Paul McGreevey & $\begin{array}{l}\text { D.E., n. 30-31, Vol. 08, jul./dic. } \\
\text { 1968. }\end{array}$ \\
\hline $\begin{array}{l}\text { Carlos Marx y Simón Bolívar. Apunte } \\
\text { sobre el liderazgo autoritario en un } \\
\text { movimiento de libertación nacional. }\end{array}$ & Hal Draper & $\begin{array}{l}\text { D.E., n. 30-31, Vol. 08, jul./dic. } \\
1968 .\end{array}$ \\
\hline $\begin{array}{l}\text { Santanderismo y Bolivarismo: dos } \\
\text { matices en pugna. }\end{array}$ & David Bushnell & $\begin{array}{l}\text { D.E., n. 30-31, Vol. 08, jul./dic. } \\
\text { 1968. }\end{array}$ \\
\hline $\begin{array}{l}\text { El Congreso de Panamá: bolivarismo } \\
\text { y monroísmo. }\end{array}$ & Indalecio Liévano Aguirre & $\begin{array}{l}\text { D.E., n. 30-31, Vol. 08, jul./dic. } \\
\text { 1968. }\end{array}$ \\
\hline $\begin{array}{l}\text { El sindicalismo boliviano: resumen } \\
\text { histórico y perspectivas actuales }\end{array}$ & Jaime Ponce G. & D.E., n. 33, Vol. 09, abr./jun. 1969. \\
\hline $\begin{array}{l}\text { Orígenes y crecimiento del partido } \\
\text { aprista y el cambio socioeconómico } \\
\text { en el Perú. }\end{array}$ & Liisa North & D.E., n. 38, Vol. 10, jul./set. 1970. \\
\hline 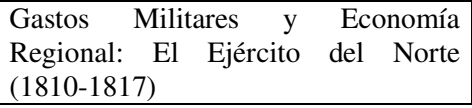 & Túlio Halperin Donghi & D.E., n. 41, Vol. 11, abr./jun. 1971. \\
\hline
\end{tabular}

Questão da propriedade da terra - Muitos artigos, como podemos constatar no quadro acima, focalizaram a problemática da terra, seja do ponto de vista do tamanho das propriedades, suas formas de exploração ou do tipo de sociedade por ela gerado. Muitos, também, foram os tempos abordados pelos autores. Alguns se dedicaram ao período colonial, outros ao proto-independente e outros, ainda, ao latifúndio já durante o período da modernização. Selecionamos alguns artigos para tecer algumas considerações historiográficas que ilustram o afirmado.

François Chevalier, historiador francês e pesquisador vinculado ao Instituto des Hautes Estudes de l'Amérique Latine de Paris, teve dois artigos seus traduzidos e publicados na Revista, ambos relativos à questão do uso e da propriedade da terra ${ }^{23}$. No primeiro deles, elaborado em 1965 e intitulado "Los problemas agrários en la América Latina de tradición indígena”, o autor referiu-se à questão agrária como um problema essencial da América Latina e, seguindo a tendência dos intelectuais de esquerda do momento, apontou a reforma agrária como "forma de resolver, num tempo mais breve possível, certos problemas como repartir a renda da terra ou a terra mesma" (p. 1) ${ }^{24}$. Nesse artigo, Chevalier chamou a atenção para a grande pressão demográfica existente sobre as terras, encontrada principalmente nos países com grande população de tradição 
indígena, os quais, desde o período colonial, tiveram seus territórios densamente povoados. Ressaltou a convivência problemática das comunidades e dos pequenos produtores com os grandes latifundiários. Reconheceu que, desde a metade ou fim do século XIX, o mundo rural passou por transformações importantes, modernizando e tomando novas formas, ao mesmo tempo em que as comunidades e pequenos produtores ficavam profundamente afetados em suas possibilidades de sobrevivência. Contudo, não deixou de identificar a permanência das estruturas coloniais nas grandes propriedades do século XX, quando afirmou:

(...) esas haciendas o grandes dominios se caracterizaron en particular por su organización social interna, basada en la dominación del patrón, por una parte, y en la servidumbre o semiservidumbre de los trabajadores con sus variantes locales por otra. (...) en las propriedades y chacras de los españoles a fin del siglo XVI, los indios residentes llamados yanaconas debían al patrón cinco días de trabajo por semana, a cambio del use de un pedazo de tierra y eventualmente de animales de trabajo(...) A cuatro siglos de distancia, constaté en diversas haciendas de los Andes Centrales la persistencia de una estructura casi exactamente parecida: contra el usufructo permanente de una parcela de tierra por los yanaconas (llamados colonos, huasipungos, etc.) éstos deben al propietario una renta perpetua en trabajos de tres, cuatro o cinco días por semana en su reserva patrimonial. (pp. 12-13)

No artigo La Gran propiedad en México desde el siglo XVI hasta comiezos del siglo XIX, que apresentara na Primeira Conferência Internacional de História Econômica, Chevalier realizou um histórico do seu objeto de estudo desde a formação até a modernização definitiva, ocorrida no governo de Porfírio Diaz. Após referir que "a la extraordinaria proliferación de las reses vacunas introducidas por los españoles se debe el comienzo de la gran propiedad en México" (p.1), o autor enfatizou que a agricultura foi explorada em regiões do centro-sul, povoadas por índios sedentários. Realizada, inicialmente, em parcelas de menor tamanho por grupos de indígenas sujeitos ao repartimiento, ao longo do século XVII, sob os efeitos da depressão, as grandes propriedades agrícolas tradicionais foram se estruturando com suas características

(...) que tiende hacia las formas semifeudales típicas de esta colonización muy extensiva y esencialmente continental, es decir, sin comunicaciones fáciles con el exterior: funciones locales de justicia, acaparadas por los señores, prisiones privadas de las haciendas para los esclavos y también para los peones indios. (p. 4) 
Reconheceu que, durante o período bourbônico, houve um crescimento da produção agrícola e certa modernização da estrutura produtiva nas propriedades agrícolas, avanços que foram comprometidos pelo clima de instabilidade gerado pelas guerras de independência, pelas guerras civis e pela invasão de índios vindos dos Estados Unidos, expulsos pela expansão anglo-saxônica para o oeste. Concluindo, o autor resumiu a interpretação defendida por alguns intelectuais acerca da modernização da grande propriedade e seus efeitos posteriores ao período por ele analisado:

Hacia el último cuarto del siglo XIX, Porfírio Díaz restablecerá la gran propiedad con la idea de que la hacienda modernizada y renovada aseguraría la prosperidad económica del país. Es entonces cuando gracias al cambio político de 1910 los peones y las comunidades de paisanos sacrificados se sublevaron e impusieron la gran reforma agraria. (p.10)

Se, no México, Chevalier constatou ter havido uma ruptura no processo de transformação da estrutura produtiva das grandes propriedades a partir do movimento de independência, o mesmo não foi identificado por William Paul Mcgreevey em seu artigo Tierra y Trabajo en Nueva Granada, 1760-1845, no qual a Colômbia foi o país focalizado. Segundo ele, apesar da historiografia sobre a independência da Colômbia destacar as mudanças políticas inerentes a alterações de elites no poder, essa interpretação "encubre una abundante continuidad en la política social, continuidad que, efectivamente, vincula el período de las reformas borbónicas y el domínio conservador del gobierno de IBogotá hasta 1845 en una sola unidad social en el tiempo.”(p.1). Nesse artigo, Mcgreevey, fundamentado em investigação documental sobre o período, analisou o tema da privatização da terra e da conseqüente exclusão social a partir de uma maneira de conceber o final do século XVIII e primeira metade do século XIX que, na atualidade, vem se mostrando prevalente nos estudos sobre história agrária na América Latina.

Segundo o autor, a política econômica de Carlos III, que impunha maior arrecadação de impostos e o crescimento da população urbana na metrópole e na colônia, pressionou para que, na região, a produção agrícola administrada por Bogotá aumentasse. Isso foi alcançado através da racionalização do esquema de posse da terra, principalmente por meio da adoção de medidas que colocaram à venda grande parte das terras reservadas aos indígenas. 
Assim, pois, o final da década de 1770 assinala uma aceleração da agressão dos brancos aos privilégios índios sobre a terra, estabelecidos no início do século XVII (...) A vagância foi um resultado do estabelecimento de direitos de propriedade não acompanhados por obrigações sociais por utilizar a terra. (pp. 15-17)

Logo após a independência, o processo de privatização de terras se intensificou, mesmo que de forma mais lenta do que ocorreu mais tarde, entre os anos de 1845-1885, quando a liderança política passou às mãos dos liberais radicais. Por um lado, os criollos trataram de transferir, aos seus domínios, as terras da Coroa (baldios, conhecidos na época colonial como realengos) que, ao longo do período colonial, nunca haviam sido alienadas do domínio público, as terras dos leais à metrópole, que retornaram ao patrimônio nacional e as terras que sempre haviam sido consideradas como arrendamentos dos índios e cuja posse pertencia à Coroa:

O governo republicano criollo, no ímpeto do zelo revolucionário, só necessitou de 66 dias para pôr em movimento o processo legal de eliminação das reservas índias ainda existentes(...). Sob a capa de promover os direitos individuais(...) negou-se sanção legal ao resguardo... e no que diz respeito à terra, deveria ser tratada como propriedade individual. (p. 21)

Ao concluir seu artigo, Mcgreevey expressou uma avaliação que começava a se fazer presente entre muitos historiadores latino-americanos da época: o período de modernização, considerado de transição a uma nova sociedade, não poderia ser analisado como de ruptura com o sistema anterior. As últimas décadas do século XVIII e as primeiras do XIX mereciam atenção especial, tendo em vista que "as políticas sociais enunciadas durante esta prolongada época de lenta mudança vão ter consequiências substanciais para o ritmo e a direção da mudança de 1845” (p. 25).

Foi também seguindo essa tendência que Túlio Halperin Donghi publicou, em 1963, o artigo La expansión ganadera en la campaña de Buenos Aires (1810-1852), que se tornou uma referência a todos os demais estudos que se seguiram sobre a produção pecuária na Argentina moderna. Nesse longo artigo de 56 páginas, Halperin focalizou o crescimento das exportações de couro realizadas através do porto de Buenos Aires, fenômeno em expansão desde o final do século XVIII. Após a independência, Buenos Aires assistiu à expansão de sua fronteira em direção ao sul da província, à gradual formação de grandes estâncias que se dedicavam à pecuária bovina e ao surgimento dos 
saladeiros, formando, assim, um sistema produtivo para atender a demanda do mercado internacional. O marco social em que ocorreu essa expansão da pecuária deu destaque aos pecuaristas e grandes latifundiários, que ascenderam na escala social e envolveram o setor mercantil, assumindo um papel político que os levou ao controle do poder. Sob o marco da história econômico-social, o autor destruiu a versão da historiografia tradicional de que a primeira metade do século XIX correspondia ao período da "barbárie", no qual as estruturas herdadas do período colonial haviam permanecido intactas e estagnadas.

O último artigo que selecionamos para expressar a importância que recebeu a questão da terra por parte dos articulistas e leitores da Revista D.E. aborda o período da modernização da estrutura produtiva. James R. Scobie, em Una revolución agrícola en Argentina, considerou que a produção de cereais e de carne de exportação, a partir de 1880, constituiu-se num elemento fundamental para a consolidação social e econômica da Argentina moderna. Afora a construção de ferrovias, a expansão do mercado interno e da população urbana, conjugadas com o fenômeno da imigração, destacou a arrendamento de terras à produção agrícola de cereais, como fator decisivo para essa transformação. Esse foi o aspecto revolucionário, na concepção do autor, introduzido pela agricultura de exportação na realidade social e econômica da Argentina, pois a pecuária havia mantido o sistema de propriedade e de ocupação de terras, provocando um grande isolamento social e cultural do camponês.

A influência da Annales ${ }^{25}$ na Desarrollo Económico - Em muitos dos artigos sobre a história da América Latina publicados na D.E. durante a década de sessenta, é possível identificar a influência da Annales, que, desde 1956, era dirigida por Fernand Braudel. ${ }^{26}$ Essa influência pode ser constatada através da publicação de textos, alguns de autoria de historiadores franceses e traduzidos especialmente para a Revista, outros, produzidos por historiadores argentinos que mostravam conhecer e adotar métodos e fontes divulgados no periódico. Durante a direção de Braudel, a Annales privilegiou a história econômico-social e promoveu um mercado comum das ciências sociais, onde a história era membro dominante, características que também vamos encontrar na D.E.

É necessário reconhecer que essa não foi a única, nem a mais importante, influência sofrida pela D.E. A conjuntura político-ideológica e a sociologia da modernização, como vimos, também orientaram a escolha dos artigos. Halperin Donghi 
(1986, p. 495) mencionou, no artigo Un Cuarto de siglo de historiografía Argentina, que a Escola dos Annales:

ofrecía a la vez inspiración más precisa, en cuanto, a falta de una común visión histórica, definía un terreno común de acción en una etapa - que se quería propedéutica - de recopilación de datos, no concebida en el espíritu de la histoire événementielle (...) Así el más prestigioso modelo historiográfico asequible al grupo renovador parecía ofrecer una doble lección: enseñaba a no temer las consecuencias de una apertura a todas las curiosidades temáticas y problemáticas, pero definía a la vez un área de tareas previas dominada por esa recolección sistemática de hechos cuantificables y seriables.

A D.E. surgiu, assim como a Revista Annales fizera na França nas décadas anteriores, acompanhando a importância que as ciências sociais assumiam no mundo acadêmico argentino. Inspirou-se na revista francesa para escrever a história através de uma história-problema, com a análise das estruturas econômicas e sociais superando o evento histórico ${ }^{27}$. Os artigos selecionados para serem publicados na D.E. buscavam compreender a estrutura social e econômica vigente na América Latina, seguindo o pensamento e a orientação que predominava entre os intelectuais de esquerda na época. Como vimos anteriormente, eles focalizavam primordialmente os acontecimentos do período colonial e proto-independente, buscando, nestes períodos históricos, a origem e formação da estrutura econômico-social dos países latino-americanos. Logo, a identificação de um problema da atualidade latino-americana - o atraso de seu desenvolvimento- orientava a investigação histórica.

Nos anos 60, o grupo da Annales, por influência de Braudel, privilegiou o estudo das estruturas econômicas e sociais como objetivo para alcançar a história total. Burke (pp. 55-56, 1991) menciona que aquele autor "era impaciente com fronteiras, separassem elas regiões ou ciências. Desejava ver as coisas em sua inteireza integrar o econômico, o social, o político e o cultural na história 'total"' .

Segundo Braudel (1969, pp. 55-56) ${ }^{28}$, a contribuição especial do historiador às ciências sociais é a consciência de que todas as "estruturas" estão sujeitas a mudanças. Os movimentos da história ocorrem em três tempos: além do ritmo breve dos acontecimentos, existem ciclos econômicos, uma conjuntura social e uma história particularmente lenta das civilizações.

A Annales, assim, dinamizou a compreensão do tempo histórico ao publicar artigos que focalizavam períodos de tempo em escala mais reduzida e introduziu novas 
fontes e metodologias de investigação. A história quantitativa, a demografia histórica e as histórias regional e serial, tendências importantes na Annales do período, também encontraram espaço na D.E. ${ }^{29}$ Nesse sentido, os textos de Frédèrik Mauro, Hacia um 'modelo intercontinental': la expansión europea en ultramar entre 1500 y 1800, onde o historiador francês defende a necessidade de uma análise qualitativa ser complementada pela quantitativa (1963); de Ruggiero Romano, Movimiento de los precios y desarrollo económico: el caso de Sudamérica en el siglo XVIII (1963); e de Túlio Halperín Donghi, Gastos militares y economía regional: el Ejército Del Norte (18101817)(1971), ambos vinculados à história regional e serial, são exemplos significativos.

Durante as décadas que se seguiram ao final da Segunda Guerra Mundial, foi grande o interesse dos intelectuais franceses sobre a história da América Latina. Isso ocorria, em parte, porque alguns, entre eles Braudel, tinham vindo ao Brasil nos anos trinta, para atuar como professores na recém-instalada Universidade de São Paulo. Formou-se, nas décadas seguintes, um grupo de discípulos desses historiadores que, seguindo as tendências metodológicas e temáticas da Annales, se dedicava ao estudo da história latino-americana. Esse é o caso de François Chevalier, F. Mauro e Ruggiero Romano.

A influência da Annales se fez sentir, também, entre os novos historiadores latino-americanos, os quais vivenciavam, nesse período, a valorização da pesquisa histórica e a profissionalização do historiador. No artigo, já citado anteriormente, $L a$ expansión ganadera en la campaña de Buenos Aires (1810-1852), Halperin Donghi analisou a expansão da pecuária na província de Buenos Aires ${ }^{30}$, utilizando inúmeras fontes como: obras literárias, como Facundo de Sarmiento, onde busca justificar dados e contrastar costumes do meio social com a análise do período que estava estudando; censos demográficos de algumas províncias argentinas; tabelas de importações e exportações da província de Buenos Aires; correspondências de comerciantes; diários de generais; estatísticas; textos clássicos; atas de Assembléia constituinte; entre outros documentos, que até então não eram de consistência para o estudo acadêmico. Fora nas publicações da Annales que essas fontes haviam sido apresentadas e utilizadas com o objetivo de integrar o sistema de produção ao meio social.

A interdisciplinaridade se constituiu em marca editorial tanto da revista francesa quanto da D.E. A abordagem que utilizava fontes diversas foi uma forma utilizada pela Escola dos Annales para disseminar a interdisciplinaridade na metodologia de trabalho historiográfico. 
François Chevalier, no artigo La gran propiedad en México desde el siglo XVI hasta comienzos del siglo XIX, também já referido, escreveu o porquê de cada disciplina ser importante para a compreensão da estrutura econômico-social dos países latinoamericanos. Afirmou que cada disciplina tem suas características próprias, seus limites, suas particularidades.

Para tener una visión tan equilibrada como posible de esos fenómenos extremadamente complejos y diversos, es indispensable, dijimos, abordar su estudio bajo el ángulo de las distintas ciencias: la economía, por supuesto que no puede ser ignorada por ninguna de las otras disciplinas; la agronomía, la antropología social y la sociología rural, representada especialmente por nuestros amigos latinoamericanos y norteamericanos que han trabajado mucho sobre el terreno en todo el continente; la geografía humana, estudiada especialmente en Francia y en el Brasil; la historia, ya que ella busca las causas profundas de los hechos y quiere comprender el presente; la psicología social, en fin, practicada más o menos empíricamente por algunas de las otras especialidades ya que, por lo que conozco, no ha sido aún aplicada científicamente a los problemas americanos que nos interesan aquí. (pp. 2-3)

Em seu artigo, o autor analisou alguns aspectos da economia, da antropologia social, direcionando-os aos pequenos produtores e aos grandes domínios, para só depois falar da reforma agrária em alguns países da América Latina. Do ponto de vista teóricometodológico, identificou o que cada disciplina tem a contribuir para o entendimento do subdesenvolvimento e para a busca do desenvolvimento latino-americano.

Mauro, por sua vez, no artigo Hacia un modelo intercontinental: la expansión europea en ultramar entre 1500 y 1800, fez uma análise da história da expansão continental européia sobre a América, África, Ásia nos séculos XVI ao XVIII. Além de basear-se na geografia dos continentes, considerando o clima e a natureza como aspectos construtivos para orientar a estrutura de sua argumentação teórica em torno do desenvolvimento do sistema econômico pré-capitalista e capitalista, o autor enfatizou a importância da história quantitativa para o conhecimento do desenvolvimento econômico do sistema capitalista ocorrido num período de longa duração e deixou clara a contribuição de outras disciplinas e metodologias:

Hace mucho que la historia ha dejado de ser la ciencia de lo excepcional. Hoy en día su objetivo es seleccionar las estructuras y las combinaciones estructurales las civilizaciones - que se hallan tras los incidentes y las contingencias. En el campo económico, las civilizaciones corresponden a sistemas y a regímenes especiales cuya naturaleza debe ser dilucidada. Pues éstos representan mecanismos generales que entran en juego cientos y miles de veces dentro del sistema, adaptándose lentamente a medida que la estructura cambia. Por cierto, 
los cambios en la estructura general son precisamente las modificaciones experimentadas por estos mecanismos generales. Comparando los mecanismos de un sistema con los de otro es posible identificar estos mecanismos y sistemas y estimar su influencia e importancia. En base a la reconstrucción de estos mecanismos pueden construirse modelos que devienen más, y más exactos a medida que progresa la investigación - en especial la investigación estadística y con la acción del progreso de la economía sobre la historia. Así el modelo, inicialmente cualitativo, se hará cuantitativo, estadístico luego dinámico. (pp. 12)

Concluindo, podemos afirmar que a Revista D.E. reuniu, entre editores, autores e público leitor, um grupo de intelectuais que, nos anos sessenta do século passado, estavam identificados, a seu modo, com a temática da latino-americanidade. Ela divulgou estudos renovados sobre a realidade atual e pretérita da América Latina de autoria de especialistas que estavam imbuídos da importância dos estudos multidisciplinares e das análises interpretativas baseadas na investigação empírica, fundamentada em metodologias atualizadas e científicas. Dentre todas as áreas de conhecimento que se fizeram presentes nos artigos publicados, a história mereceu destaque especial e, mais ainda, apresentou-se de forma renovada. A investigação histórica, baseada em temas da história econômico-social, em problemas, fontes e métodos, que apareceram primeiramente na Annales e que, mais tarde, a Nova História iria consagrar, permitiram que participassem, da rede de intelectuais que a D.E. congregava, historiadores de alto nível que, até os dias atuais, ocupam lugar de destaque na produção historiográfica sobre a América Latina.

\section{Referências Bibliográficas}

BURKE, Peter. A Escola dos Annales, 1929-1989. São Paulo: Unesp, 1991. 154p. . Los problemas agrarios en la América Latina de tradición indígena. Desarrollo Económico, Argentina, v. 6, 1966.

CHEVALIER, Francisco. La gran propiedad en México desde el siglo XVI hasta comienzos del siglo XIX. Desarrollo Económico, Argentina, v. 3, 1963.

DONGHI, Túlio H. Gastos militares y economía regional: el Ejército Del Norte (18101817). Desarrollo Económico, Argentina, v. 11, 1971.

. La expansión ganadera en la campaña de Bueno Aires (1810-1852). Desarrollo

Económico, Argentina, v. 3, 1963. 
FONTANA, Josep. A história dos homens. Bauru: Edusc, 2004. 506p.

GRAMSCI, A. Os intelectuais e a formação da cultura. São Paulo: Círculo do Livro, 1981.

GRESPAN, Jorge. O estruturalismo da CEPAL na obra de Raúl Prébisch. História Unisinos. São Leopoldo, v. 5, pp. 105-125, 2001.

KAPLAN, Marcos. 50 años de historia Argentina (1925-1975): el labirinto de la frustración. In: CASANOVA, Gonzáles. América Latina: historia de medio siglo. México: Siglo XXI, 1979. v. 1.

MAURO, F. Hacia un modelo intercontinental: la expansión europea en ultramar entre 1500 y 1800. Desarrollo Económico, Argentina, v. 3, 1963.

MCGREEVEY, William P. Tierra y trabajo en Nueva Granada, 1760-1845. Desarrollo Económico, Argentina, v. 8, 1968.

REIS, J. Carlos. Nouvelle Histoire e tempo histórico. A contribuição de Febvre, Bloch e Braudel. São Paulo: Ática, 1994. 165p.

ROMANO, Ruggiero. Movimiento de los precios y desarrollo económico. El caso de Sudamérica en el siglo XVIII. Desarrollo Económico, Argentina. v. 3, 1963.

SARLO, Beatriz. La batalla de las ideas (1943-1973). Buenos Aires: Biblioteca del Pensamiento Argentino, Ariel, 2001. 468p.

SCOBIE, James R. Una revolución agrícola en la Argentina. DesarrolloEconómico, Argentina, v. 3, 1963.

SIRINELLI. J. F. Os intelectuais In: RÉMOND, René. Por uma história política. Rio de Janeiro: UFRJ, 1996. 464p.

SORJ, Bernardo. A construção Intelectual do Brasil contemporâneo. Rio de Janeiro: Jorge Zahar, 2001. 135p.

www.ides.org.ar/revista/, 31/08/2006 às 13h:28min.

REICHEL, Heloisa Jochims; BRONICZACK, Ana Paula da Silva e EHLERT, Débora. The Latin America history at Desarrollo Económico magazine in the sixties years of the last century História, São Paulo, v. 25, n. 1, p. 203-225, 2006.

Abstract: The present article analyses the Latin America historiography published in the Argentinean periodical called Desarrollo Económico- Revista de Ciencias Sociales during the 60's of the last century, which is a period that shows instability in politics and intellectuals great interest in analysing the Latin American historic process. It identifies the predominant themes among the published articles about Latin American history, analyses the land property 
issue, the influence of another magazine, called Annales, the predominance of both economical and social history, also pointing to the new investigative methodologies used by historians. The conclusion shows the latin-american perspective present at the published articles and the fact that many of them are already the predecessors of modern trends in Argentinean and Latin American historiography.

Keywords: Intellectuals, Desarrollo Económico magazine, the 60's, Latin American history, agricultural history, Annales: economies, sociétés, civilizations magazine

Artigo recebido em 09/2006. Aprovado em 10/2006.

\section{NOTAS}

\footnotetext{
* Professora do Programa de Pós-Graduação em História da Universidade do Vale do Rio dos Sinos - Unisinos. Avenida Unisinos, 950. CEP: 93022-000. São Leopoldo, Rio Grande do Sul/RS, Brasil

** Graduanda em História pela Universidade do Vale do Rio dos Sinos - Unisinos / Bolsista de Iniciação Científica Fapergs.

Graduanda em História pela Universidade do Vale do Rio dos Sinos - Unisinos/ Bolsista de Iniciação Científica $\mathrm{CNPq} /$ Pibic.

${ }^{1}$ A definição de intelectual baseada na noção de engajamento na vida de uma comunidade como ator, testemunha ou consciência encontra-se desenvolvida em SIRINELLI, J. F. Apud: RÉMOND, René, 1996, p. 243.

${ }^{2} \mathrm{Na}$ obra Os intelectuais e a organização da cultura, Gramsci (1981) destaca que cada grupo social cria para si, de um modo orgânico, uma ou mais camadas de intelectuais, os quais se tornarão responsáveis pela elaboração de uma teoria que permitirá uma relativa homogeneidade entre a classe, tanto na esfera econômica, quanto na política, ou na
} social.

3 Ver mais sobre isso em SARLO (2001) e SORJ (2001).

${ }^{4}$ Cabe referir que os primeiros quatro números da Revista foram publicados nos anos de 1958 e 1959 pela Junta de Planificación Económica de la Província de Buenos Aires, presidida por Aldo Ferrer e aparecem, nos índices da Revista, como volume 0 , números 1, 2, 3 e 4.

${ }^{5}$ Palavras que estão no site da revista: www.ides.org.ar/revista, “...La continuidad de esta empresa intelectual ha sido el fruto de la perseverancia de los hombres e de las mujeres que se sucedieron en ella desde los ya lejanos días de 1958, manteniendo el compromiso original: encarar el análisis y la comprensión de los problemas del país con rigor Académico, desde una perspectiva muldisciplinaria y en el marco del respecto a la pluralidad de ideas [...] A lo largo de los años las condiciones en que debieron desarrollar su labor no siempre fueron las mejores. No obstante ello, sobreponiéndose a coyunturas difíciles, lograron asegurar la regularidad de la Revista, se esforzaron por mantener su nivel y hicieron posible que ésta ganara el reconocimiento que tiene en la actualidad entre las publicaciones de ciencias sociales en América Latina."

${ }^{6}$ Informações contidas no site: www.ides.org.ar/revista/.

${ }^{7}$ Veja o que diz o site do IDES “...manteniendo el compromisso original: encarar el análisis y la comprensión de los problemas del país con rigor Académico, desde una perspectiva muldisciplinaria y en el marco del respecto a la pluralidad de ideas..."

${ }^{8}$ Comitê Editorial: Nuestros primeros veinticinco años. In: Desarrollo Económico, Revista de Ciencias Sociales, Buenos Aires, v. 25, p. 483, 1986.

${ }^{9}$ Os anos finais da década de 1950 foram assinalados por uma destacada renovação das ciências sociais na Argentina, momento em que ocorreu a profissionalização da carreira e a instalação da licenciatura em Sociologia na Universidade de Buenos Aires.

${ }^{10}$ Comitê Editorial: Nuestros primeros veinticinco años. In: Desarrollo Económico, Revista de Ciencias Sociales, Buenos Aires, v. 25, pp. 483-484, 1986.

${ }^{11}$ Há inúmeros estudos que focalizam o pensamento cepalino. Um dos que, mais recentemente, o resenha e avalia é GRESPAN, Jorge. O estruturalismo da CEPAL na obra de Raúl Prébisch. História Unisinos, v. 5, pp. 105-125, 2001.

${ }^{12}$ Assim como com a sociologia, a profissionalização da carreira de historiador também teve seu início nesse momento. Três centros de pesquisa se formaram sob os auspícios institucionais das universidades: O Instituto de Investigaciones Históricas de Rosário, o de Estudios de Historia Social de Buenos Aires e o de Estudios Americanistas de la Universidad Nacional de Córdoba (ver mais em HALPERIN DONGHI, Túlio. "Un cuarto de Siglo de Historiografiía Argentina. pp. 487-520).

${ }^{13}$ A história econômica e social era desenvolvida, desde os inícios do século XX, como alternativa à história política, preferida dos historiadores positivistas. Segundo Josep Fontana (2004, p. 261), "Ao falar de história econômica e 
social, em termos gerais, nos referimos ao conjunto de respostas que foram dadas à insatisfação com o velho modelo de história limitado à atividade política e, de maneira tangencial, à 'alta cultura', que dedicava-se sobretudo à atuação das minorias dirigentes. Elas tinham, em comum, a vontade de integrar, na análise, os dados referentes à atividade econômica - ao trabalho, à subsistência, à produção e às trocas - e o propósito de abarcar o conjunto da sociedade".

${ }^{14}$ A Editorial Universitária de Buenos Aires - Eudeba - foi criada em 1958 como parte da política de extensão social dos bens e serviços levada a cabo pela Universidade de Buenos Aires entre os anos de 1956 e 1966, quando reitores humanistas, como Jose Luis Romero, estiveram no seu comando. Dirigida por Boris Spivacow, a editora publicou, até a intervenção em 1966, 802 títulos e quase doze milhões de exemplares, modificando sensivelmente o mercado do livro.

${ }^{15}$ Roberto Córtes Conde, Guido Di Tella, e Silvia Sigal são outros nomes presentes no volume.

${ }^{16}$ Editado em 1969 por Jorge Alvarez, esse foi um livro exitoso que contou com a colaboração, entre outros intelectuais,de José Carlos Chiaramonte, Ezequiel Gallo, Aldo Ferrer, Gino Germani e Roberto Cortés Conde.

${ }^{17}$ Expressão utilizada por KAPLAN (1979, p. 36).

${ }^{18}$ Apud SARLO, 2001, p. 68.

${ }^{19}$ No início dos anos setenta, ocorreram conquistas do movimento estudantil, como a imposição de professores progressistas ou peronistas antiimperialistas nos cursos de humanidades e arquitetura. Fundaram-se as "cátedras nacionais", cujos alunos se inscreviam no que eles mesmos chamavam de "epistemologia terceiro-mundista".

${ }^{20}$ Ao longo dos dez anos analisados, foram publicados 188 artigos originais e completos, sendo que 107 se referiam a temas relativos à América Latina em geral ou a algum(ns) de seus países. Sobre temas relativos à história da América Latina e geral, foram publicados 35 artigos.

${ }^{21}$ Tendo em vista que tanto o capital quanto o mercado consumidor eram gerados pelo setor externo da economia, ou seja, dependiam dos resultados das exportações.

22 É importante destacar que, atualmente, os estudos historiográficos sobre o período colonial tendem a afirmar que a grande propriedade convivia com outros tipos de unidades produtivas e que a sociedade se compunha de vários grupos rurais e urbanos que não se encontravam exclusivamente submetidos à grande propriedade. E mais, que o processo de concentração e privatização da terra e da riqueza passou a se desenvolver mais intensamente apenas no final do período colonial, consolidando-se ao longo do período independente.

${ }^{23}$ Convém destacar o grande interesse que a América Latina despertava entre os pesquisadores europeus, principalmente franceses, nas décadas focalizadas. Naqueles anos, a África começava a interessar, configurando, com os países latino-americanos, o que se chamava de Terceiro Mundo. Hoje, esse interesse se desloca para os países do extremo e médio oriente.

${ }^{24}$ É preciso salientar que a numeração das páginas dos artigos da D.E. citados nesse artigo segue a ordem de impressão numérica do site e não da revista impressa. Exceto o artigo de Túlio Halpering Donghi, Un cuarto de siglo de historiografia Argentina, que foi retirado do periódico impresso.

${ }^{25}$ A Revista Annales, publicada na França, foi criada em 1929. Embora o grupo a ela associado seja chamado, por muitos, de a "Escola dos Annales", seus membros, segundo Burke, negam a existência de uma escola, preferindo destacar as diferentes etapas e contribuições individuais existentes na Revista.

${ }^{26}$ Braudel dirigiu a revista até 1972, sucedendo a Lucien Febvre, seu fundador, junto com Marc Bloch.

${ }^{27}$ A D.E. nada ou quase nada publicou sobre a história das mentalidades. No período analisado, há, na seção Notas e comentários, uma apreciação de Ernesto Laclau, intitulada Historia de las mentalidades, 1963. pp. 9/10.

${ }^{28}$ Braudel, Apud: Burker, 1991. pp. 55-56.

${ }^{29}$.Mais sobre o assunto em J. Carlos Reis (1994).

${ }^{30}$ Estuda o sistema de desenvolvimento da pecuária, no período pós-independente, e a sua dinâmica na gestação da formação econômica e social capitalista da Argentina. 